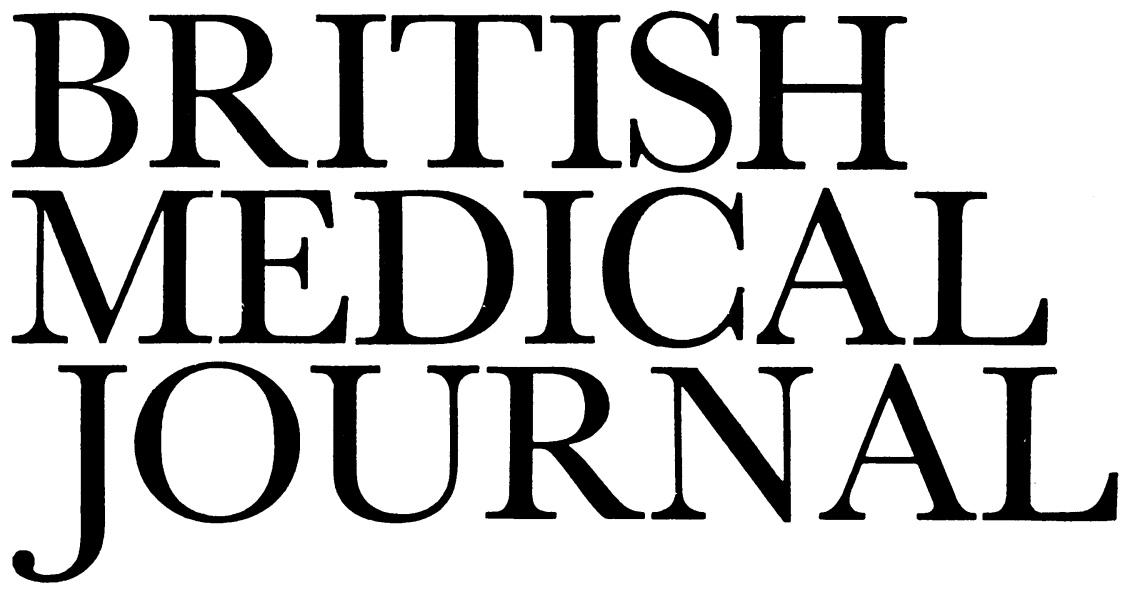

\title{
Prostatic carcinoma
}

Advances in medical knowledge may sometimes turn one generation's certainties into the next generation's doubts. Certainly this is true of the management of prostatic adenocarcinoma Radical (perhaps more correctly described as "total") prostatectomy was first performed by Hugh Hampton Young at Johns Hopkins Hospital in the first decade of this century. ${ }^{1}$ British urologists have never taken to this operation, but in the United States for many years surgical removal of the prostate with an early tumour was accepted without question as being so effective in curing so many patients that the price was thought reasonableimpotence in almost all patients and urinary incontinence in many. ${ }^{2}$ In the 1940 s, with recognition of the hormonal sensitivity of prostatic carcinoma, patients were treated with stilboestrol. ${ }^{3}$ This rapidly came to be considered as good management for almost all patients with prostatic carcinoma, and many patients were treated at the merest suspicion of the disease. Indeed, I suspect there are still patients in Britain who have been taking stilboestrol for years on the basis of a "prostate that feels hard" who never have and never will have a prostatic carcinoma.

More recently there has been increasing interest in controlling or possibly even curing the early localised tumour $^{4}$ by radiotherapy, either by external beam ${ }^{5}$ or by interstitial implantation of radioactive seeds. ${ }^{6}$ Certainly it seems illogical to treat the patient with systemic hormones if metastatic spread has not occurred and a reliable local treatment is available. Well tried methods seem, therefore, to be available for treating both localised prostatic tumours and widespread disease. So what is the problem? It was stated very clearly in 1982 by Tom Stamey, of Stanford University Medical Center, California, one of the most respected members of the American urological community. ${ }^{7}$ His monograph on prostatic carcinoma opened with the words "I do not know how to treat carcinoma of the prostate." Many urologists share his doubts.

The first thing to say is that carcinoma of the prostate is very common indeed. Necropsy studies and critical analysis of prostates removed or resected for benign disease have shown an increasing incidence of prostatic carcinoma with age. ${ }^{8}$ Thirty per cent of men over the age of 50 and something like $90 \%$ of men aged 90 will have such carcinomas on histological examination. Are these so called "incidental" carcinomas merely histological oddities, or do they represent the beginnings of what could become clinical disease? Perhaps the evidence favours the latter. ${ }^{9}$ Yet even those patients known to suffer from early carcinoma of the prostate are at a considerably less risk of dying from their prostatic tumours than from other conditions such as cardiovascular disease. ${ }^{10}$

The paradox is now apparent. In some-indeed, all too many-men carcinoma of the prostate is a virulent, life threatening, and unpleasant disease. On the other hand, most men who live long enough will in fact develop such a tumour without ever knowing it, and even those with overt disease are as a group more at risk from dying of other causes. These facts explain why assessing the treatment of prostatic carcinoma is so difficult. Furthermore, both radical surgery and treatment with oestrogens had become established treatments before the concept of the controlled clinical trial developed; and once a method of treatment has become accepted it is very rarely subjected to such a trial.

Surgeons who practise radical prostatectomy can point to 15 year survivals of $30 \%$ or thereabouts in patients undergoing this operation, " but there is evidence to suggest that patients with prostatic carcinoma early enough to be suitable for management by this operation may have a comparable expectation of survival without any treatment at all. ${ }^{12}$ Hormonal treatment received a great blow from the first Veterans Administration study performed in America, which raised doubts about any improvement in survival in patients treated with stilboestrol and indeed showed that rather than benefiting many patients the drug carried its own lethal hazards in the form of an increased incidence of cardiovascular disease. ${ }^{13}$ One immediate benefit from these studies was recognition that the dosage of stilboestrol being prescribed at that time was too high (a 1965 edition of a standard surgical textbook suggested 25 times the dose in use today). Possibly the message that we were slower to grasp was that by no means all patients should be receiving this treatment. The Americans rather than the British seem to have taken the latter lesson to heart-despite their more aggressive surgical approach to early disease. ${ }^{14}$

What, therefore, can we say about the hormonal treatment of prostatic carcinoma? Firstly, stilboestrol (or other oestrogens) do carry a risk even in the currently used low doses, and this risk is probably unacceptable in those with a previous history of cardiac or vascular disease. Increasingly urologists are recommending orchiectomy as the hormonal treatment of choice in such patients. ${ }^{15}$ This avoids the potentially lethal side effects of oestrogens, and the patient is not embarrassed by gynaecomastia-nor need he try to remember to take his pills every day (an important consideration in the elderly). Some patients will not tolerate 
the concept of castration, although the subcapsular operation which leaves a palpable organ within the scrotum is usually more acceptable. When asked, however, which patients should undergo this operation, like Stamey, I do not know.' No one would withhold treatment from a man presenting with advanced disease-with, for example, painful bony metastases or ureteric obstruction. Such a patient would have perhaps an $80 \%$ chance of remission after orchiectomy ${ }^{16}$ but inevitably it will be only temporary (though the patient may die from some other cause meantime) and may not increase length of life.

The problem is the patient with earlier disease. What do we do for the man presenting with outflow obstruction of the bladder who is suspected on clinical grounds of having a prostatic carcinoma or in whom the diagnosis is first made when the pathologist reports his findings on examination of chips from the transurethral resection? This patient may either be free of metastases or on investigation be found to have metastatic disease in the skeleton which is not the source of any symptoms. Hormonal treatment is the only effective systemic treatment available for this stage of prostatic carcinoma. ${ }^{16}$ Do we treat the patient who is asymptomatic knowing that if and when he develops his painful metastases we would then have little to offer him, or do we wait until he has symptoms, relief of which will make any ill effects of hormonal treatment more acceptable?

On theoretical grounds it may be argued that early treatment when the total tumour bulk is small ought to be more efficient. Certainly transrectal ultrasound has shown a continuing growth of tumours in patients who have not received hormonal therapy. ${ }^{17}$ Yet if early hormonal treatment was beneficial we might expect patients so treated to survive longer, but as yet there is no evidence that they do. Furthermore, by deferring treatment in the patient who is asymptomatic until symptoms occur we might gain a second symptom free period after orchiectomy. The sum of these two periods might produce a total symptom free interval longer than the one achieved by early hormonal treatment in the asymptomatic patient. Again there is no evidence that this is so. Personally, I am always distressed when a patient who has received early hormonal treatment develops symptoms, because I know that the only effective medical treatment I have to offer him has already been given at a time when he was well.

Alternatives to oestrogen are becoming available for hormonal treatment. Antiandrogens such as cyproterone acetate, ${ }^{18}$ luteinising hormone releasing hormone analogues, ${ }^{19}$ and the antifungal agent ketoconazole ${ }^{20}$ (in high dosage) are certainly effective. Estramustine phosphate may act both as an oestrogen and as a cytotoxic drug. ${ }^{21}$ Despite some enthusiasm for their use in the United States true cytotoxic drugs have not so far been very promising. ${ }^{22}$ Can we really decide what streatment is best, however, if the fundamental questions have yet to be answered-which patients need treatment and when treatment should be started?

With a view to contributing to the solution of this problem the Medical Research Council Working Party on Urological Cancer is organising a large scale collaborative study of the treatment of prostatic carcinoma. Patients with advanced local disease or asymptomatic metastatic disease will be allocated to one of two groups. The first group will undergo an orchiectomy immediately while the other will receive no treatment initially but will undergo orchiectomy wher the disease progresses (for example, when patients develop painful metastases). The patients will be followed up to compare both the symptom free period and the total survival from each treatment. Many urologists believe that a study of this sort is essential. Many people will be surprised that such a study has not been done before 1985. Experience of the Veterans Administration studies, however, shows that the sort of differences for which we are looking will emerge only in a study of many patients. ${ }^{13}$ About 8000 patients in Britain present with prostatic carcinoma each year, and most of these would be eligible to enter this study. I hope that all treating prostatic carcinoma-be they urologists, general surgeons, or oncologists-will see these studies as important and enter patients into one or other of them. The Medical Research Council study is designed to be as simple as possibleprobably no simpler collaborative study has yet to be devised. Those entering patients to the study will not be expected to perform any complex investigations, and the amount of extra work required over and above the routine treatment of the patient will be minimal. Each of the options being compared is widely practised by many urologists (and others), and since each group believes that its policy is correct there could be little ethical objection to comparing the two.

Tom Stamey believes that if Hugh Hampton Young had treated only half his patients by total radical prostatectomy rather than all of them the current controversy concerning that operation would never have existed. Much the same could be said about hormonal treatment. Those of us who, like Tom Stamey, are genuinely uncertain how we should be treating our patients should soon have some concrete information to help us.

DAVID KIRK

Consultant Urologist,

Royal Infirmary,

Glasgow G31 2ER

1 Young $\mathrm{HH}$. The early diagnosis and radical cure of carcinoma of the prostate. Bulletin of the Johns Hopkins Hospital 1905;16:315-21.

2 Culp OS, Meyer JJ. Radical prostatectomy in the treatment of prostatic cancer. Cancer 1973;32:1113-8.

3 Huggins C, Hodges CV. Studies on prostate cancer. Cancer Res 1941;1:293-7.

4 Ray GR, Cassady JR, Bagshaw MA. Definitive radiation therapy of carcinoma of the prostate. Radiology 1973;106:407-18.

5 Bagshaw MA. External radiation therapy of carcinoma of the prostate. Cancer 1980;45(suppl): 1912-21.

6 Herr HW. Iodine-125 implantation in the management of localised prostatic carcinoma. Urol Clin North Am 1980;7:605-13.

7 Stamey TA. Cancer of the prostate: an analysis of some important contributions and dilemmas. Monographs in Urology 1982;3:65-96.

8 Franks LM. Latent carcinoma of the prostate. F Pathol Bacteriol 1954;68:603-16.

$9 \mathrm{McNeal}$ JE. Origin and development of carcinoma in the prostate. Cancer 1969;23:24-34.

10 Barnes R, Hadley H, Axford P, Kronholm S. Conservative treatment of early carcinoma of prostate. Urology 1979;14:359-62.

11 Jewitt HJ. The case for radical perineal prostatectomy. $\mathcal{F}$ Urol 1970;103:195-9.

12 Barnes RW. Prostate cancer. Survival with conservative therapy. JAMA 1969;210:331-2.

13 Byar DP. The Veterans Administration Cooperative Urological Research Group's studies of cancer of the prostate. Cancer 1973;32:1126-30.

14 Lepor H, Ross A, Walsh PC. The influence of hormonal therapy on survival of men with advanced prostatic cancer. $\mathcal{I}$ Urol 1982;128:335-40.

15 Klugo RC, Farah RN, Cerny JC. Bilateral orchiectomy for carcinoma of prostate: response of serum testosterone and clinical response to subsequent oestrogen therapy. Urology 1981;17: $49-50$

16 Resnick MI, Grayhack JT. Treatment of stage IV carcinoma of the prostate. Urol Clin North Am 1975;2:141-61.

17 Peeling B. Castration for prostatic carcinoma still an alternative form of therapy? In: Schröder FH, ed. Androgens and anti-androgens. Weesp: Schering, 1982:125-31.

18 Wein AJ, Murphy JJ. Experience in the treatment of prostatic carcinoma with cyproterone acetate. F Urol 1973;109:68-70.

19 Allen JM, O'Shea JP, Mashiter K, Williams G, Bloom SR. Advanced carcinoma of the prostate: treatment with a gonadotrophin hormone agonist. Br Med $\mathcal{J}$ 1983;286: 1607-9.

20 Trachtenberg J, Pont A. Ketoconazole therapy for advanced prostate cancer. Lancet 1984;ii:

21 Slack NH, Brady MF, Murphy GP. Observations of prolonged use of oral Emcyt in prostatic cancer patients. Urology 1982;20:515-23.

22 Scott WW, Gibbons RP, Johnson DE, Prout GR, Schmidt JD, Saroff J, Murphy GP. The continued evaluation of the effects of chemotherapy in patients with advanced carcinoma of the prostate. $\mathcal{F}$ Urol 1976;116:211-3. 